\title{
Lateral Wall of the Bladder
}

National Cancer Institute

\section{Source}

National Cancer Institute. Lateral Wall of the Bladder. NCI Thesaurus. Code C12333.

The aspect of the bladder wall that is located on the side. 